\title{
PARENTAL EDUCATION AND FAMILY STATUS - ASSOCIATION WITH CHILDREN'S CIGARETTE SMOKING
}

\author{
Iva Žaloudíková', Drahoslava Hrubáá, Ibrahim Samara² \\ 'Department of Psychology, Faculty of Education, Masaryk University, Brno, Czech Republic \\ 2Department of Preventive Medicine, Faculty of Medicine, Masaryk University, Brno, Czech Republic
}

\section{SUMMARY}

Background: Social influences are among the most important factors associated with children's and adolescents' smoking. Social norms in families, peer groups, professional and municipal communities influence the individuals ones by the process of socialization obtained mainly by interactions and observations. Especially social context of the home environment expressed by household smoking restriction serves as a socialization mechanism that dissuades from the using of tobacco. Parental anti-smoking socialization practices (their attitudes and knowledge about children smoking, discussion about smoking in appropriate quality and frequency, smoking environment in homes) are influenced by their education and family status.

Methods: Markers of social environment (the level of mothers' and fathers' education, family status) were investigated during interview with 5th graders included in the cohort participating in the programme "Non-smoking Is Normal". Data about the self-reported exposure to passive smoking at homes and cars were taken into consideration. Information about discussions with parents about smoking, opinions about adults smoking, experimentation with smoking, and concurrent decision about smoking in the future were obtained from 766 children aged 11 years. Those who did not know parental education or family status were excluded from the evaluation. Differences were evaluated using the chi-square, MantelHaenszel, Fisher and Yates corrected tests in the statistic software Epi Info, version 6.

Results: The level of mothers' and fathers' education significantly influenced the exposure of children to passive smoking. Compared to families of higher educated parents, children living in families with middle and low levels of parents' education were significantly more exposed to environmental tobacco smoke at home and in $\operatorname{car}(\mathrm{RR} 1.38 ; 95 \% \mathrm{Cl} 1.04-1.83)$ and fewer of them live in non-smoking environments. In the whole cohort, $67.5 \%$ children have not smoked even one puff yet, $17.2 \%$ reported one single attempt, and $15.4 \%$ smoked repeatedly. The level of parents' education had no influence on children's concurrent smoking experimentation or on their concurrent decision about smoking in the future. There was also no difference in number of children who obtained cigarettes from their parents and parents' level of education (about $6 \%$ ). When the level of maternal education was combined with the family status, significant differences were found. Compared to children living with two biological parents (highly educated mother), children from other groups more often reported current experimentating with smoking and lower number of those decided not to smoke in the future. No significant differences were found in other markers of knowledge and attitudes between children from analysed social family groups.

Conclusion: In our study, the parental education has significantly influenced exposure of children to passive smoking at homes and in cars, but had no effect on children's opinions and attitudes about smoking. Higher education of mothers and family status significantly lowered the frequency of current experimentation and decision about future smoking among children living in families with two biological parents of whom mother attained higher education. It is necessary to seek ways for improving parental concern about smoking prevention.

Key words: social factors, parental education, family status, passive smoking, active smoking, schoolchildren

Address for correspondence: D. Hrubá, Dept. of Preventive Medicine, Faculty of Medicine, Masaryk University, Kamenice 5, 62500 Brno, Czech Republic. E-mail: hruba@med.muni.cz

\section{INTRODUCTION}

The prevention of children's smoking must be one of the nation's health priority as smoking during childhood and adolescence is a very important medical and social problem: the earlier experimentation and initiation of smoking increases the likelihood of habituation and consequently worsens negative health outcomes (1). Risk behaviours tend to cluster together and are associated with other negative outcomes such as poor school performance, school misbehaviour, delinquency and premature sexual activity (2). Social influences are among the most impor- tant factors associated with children's and adolescents' smoking, diet, sexual intercourse, and other substance use, as teens are particularly susceptible to these factors $(3,4)$.

Individual people are included into the group memberships in families, school and occupational communities, neighbours, and religious or leisure-time institutions. Each of them has the specific social norms of acceptable beliefs, attitudes and behaviour (5). These social norms influence the members of community who accept and confirm them through the process of socialization (6). Direct and primary social influence occurs within the family, peer affiliation becomes more important and influential during adolescence (4). 
Group memberships in family, school, and peer communities are powerful socializing experiences, and people are very often able to change their perception, opinions and behaviour to be consistent with standards or expectations of the group (5). Susceptibility to peer influences may vary by gender, race, and age (7). Several studies have found that depressed adolescents are more susceptible to social factors associated with smoking, namely with perceived prevalence of smokers and pro-smoking normative beliefs (8).

Many studies have described, that the risk of starting smoking increases steadily with age up to age of 16 ; then the risk decreases significantly, especially after the age of 18 (9). Also the internal problems such as depression are more common in adolescent age (10). Individual children seek out peers with similar norms and behaviour in the process of selection, and especially depressed individuals need the acceptance by peers (11). The selection process includes also exclusion of those who do not adhere to social norms of the group (12).

Among several theories, non of them fully explains social influence, but majority of them declare that people learn through social interactions. The most important and primary role have relationships within the close community membership (family, peers, neighbours), while media and other cultural tools have secondary, nevertheless, important influence (6).

There are at least two plausible mechanisms of socialization: a) smoking parents and other close family members perceived as models of behaviour, they provide positive attitudes towards smoking and offer easier access to cigarettes; b) the level of smoking bans at home and in vehicles may constitute a norm or unacceptable message, when smoking is or is not appropriate (13)

Parental smoking has been repeatedly described in association with higher rates of children's experimentation with smoking (14-21). Parental smoking may shape children's cognitive understanding regarding the acceptability of smoking before smoking initiation (22). Children of smoking parents might easily obtain cigarettes within the household. Warning against smoking might be less credible for them (9). Some studies found the different levels of influence by mothers' smoking and fathers' smoking (23), while others did not confirm these findings (9).

The crucial role of peer groups was confirmed repeatedly (24). Similarly smoking/no-smoking behaviour among friends is the result of social selection and social influence. Previous research also indicated that position of a child within group structures (reciprocal or non-reciprocal friendship) may influence his/her smoking behaviour by different ways $(24,25)$.

Social context of the home environment can also be expressed by household smoking restriction. Youth living in homes with total bans were significantly less susceptible to try and experiment with smoking. On the other hand, a lack of household smoking restrictions is associated with a higher degree of smoking susceptibility $(13,16,26)$.

Also exposure to smoking in vehicles is strongly associated with a higher risk of smoking experimentations and uptake (13). Efforts for banning smoking in cars with children is consistent with recent air quality monitoring showing that smoking in cars can produce biologically active levels of dangerous chemicals emitted by cigarette smoke $(27,28)$. Now it is generally accepted that banning smoking in vehicles is another useful anti-smoking parental strategy for non-smoking children, particularly under the age 15, even if the parents themselves are smokers (29).

Parental anti-smoking socialization practices includes namely: a) parental attitudes and knowledge about their children's smoking behaviour; b) parental discussion with children about smoking in appropriate quantity and frequency; c) smoking environment in children's homes (29). Lack of parental concern and social support, family bonds, family conflicts, weak or excessive control, inconsistent discipline, and ineffective parental monitoring of child behaviour and activities are associated with smoking of adolescents (30).

Other important factors of prevention strategy are appropriate ways of parental communication, anti-smoking messages, and forms of setting rules (31). Quality of the smoking-specific discussions in a constructive and respectful manner can prevent children from smoking (32). Young people's percention of such parental anti-smoking intervention is crucial $(33,34)$. According to the frequency of anti-smoking communication, the results may be different: in some studies no association with children's smoking was found out (35), other suggested that frequent discussions may reduce smoking escalation among experimenting adolescents $(32,36)$.

One of the most important socializing agents is the family and its structure. Parents serve not only as role models, but they are sources of different levels of support and control. Many studies described that family structure is related to children's and adolescents' health and well-being (2).

At present the majority of studies are targeting teenagers and young adults. The educational programme for primary antismoking intervention "Non-smoking Is Normal" was therefore developed for younger children attending the 1 st to 5 th grade of primary school. The influence of the programme was evaluated in a semi-longitudinal prospective study including cohorts of children from 23 primary schools which voluntarily accepted this programme and the same number of controls from the same region. Together, the sample involved 766 children (385 from the programme group, 382 from the control group), $49.7 \%$ were boys and $50.3 \%$ were girls. This paper describes the relationship between parental level of education, family status, and smoking opinions and experiments of their children.

\section{METHODS}

The Non-smoking Is Normal Programme and its effects were evaluated twice a year by sets of pre-tests (performed one month before the series of 6 lectures) and post-tests ( 4 months after the end of the last lecture). There were some serious limitations to obtain data from our participants as the target group in the programme includes cohort of young children aged 6-11 years. Some questions were repeatedly filled in every time of the data collection, but the chosen markers of social environment (the level of mothers' and fathers' education, family status) were included only at the 5 th grade. Teachers were asked to help children to understand three levels of education (low - elementary school and comprehensive school and/or authorized skill training - up to 11 years; middle - grammar school with the state examination - 12 years; high - university, college 15-18 years) and three types of family structure: a) complete with two biological 
parents; b) reconstituted with one step-parent; c) single with only one biological parent). The married/cohabiting family status was not distinguished.

Two questions were aimed at the exposure of a child to passive smoking at home and in car, one concerned with communication on smoking with parent and one about child's ability to protect himself/herself against exposure to passive smoking. Children's opinions about smokers were expressed by their assessment of adults smoking by five-point scale ( 1 = "I like it", 5 = "I displease it"), and by their knowledge of possible smokers dependence and higher risk of alcohol and drugs abuse. Children described their past and current smoking habit as "never even one puff", "one attempt", "smoked repeatedly" and current opinion about future smoking ("certainly not", "probably not", "not know yet", "probably yes", "certainly yes"). Those who tried to smoke or smoked repeatedly were asked about the source of cigarettes, and the impressions after the first attempt.

The differences were assessed in the Epi Info statistic software, version 6, using chi-square, Mantel-Haenszel, Fischer, and Yates corrected tests.

\section{RESULTS}

Together 766 children (aged 11 years) filled in the questionnaire, but less of them were informed about their parents' education ( $87.6 \%$ filled mothers' and $82.6 \%$ filled fathers' education). The differences between prevalence of mothers' and fathers' education levels were not significant. On the other hand, only $1.8 \%$ of respondents didn't answer questions about family status (Table 1). The differences within the groups of families with two biological parents with respect to their level of education were not significant.

The level of parental education significantly influenced the exposure of children to passive smoking. In families with higher educated parents, majority of children (about 60\%) are never exposed and only about $15 \%$ are daily exposed to passive smoking. Compared to higher educated parents, children living in families with middle and low levels of education are significantly more frequently exposed to environmental tobacco smoke. The similar trends were found for children's exposure to smoking in cars. The parental education did not influence the prevalence of

Table 1. Characteristics of the group

\begin{tabular}{|l|c|c|}
\hline Whole sample = 766 children & $\begin{array}{c}\text { Mother's } \\
\text { education }\end{array}$ & $\begin{array}{c}\text { Father's } \\
\text { education }\end{array}$ \\
\hline Number of answers & 671 & 633 \\
\hline Low = up to 11 years & $8.3 \%$ & $8.5 \%$ \\
\hline Middle = 12 years, state exam & $64.1 \%$ & $59.0 \%$ \\
\hline High = 13 and more years & $27.6 \%$ & $32.5 \%$ \\
\hline Family structure & \multicolumn{2}{|c|}{751} \\
\hline Number of answers & \multicolumn{2}{|c|}{$12.0 \%$} \\
\hline Complete (2 biological parents) & \multicolumn{2}{|c|}{$10.7 \%$} \\
\hline Reconstituted (1 step parent) & \multicolumn{2}{|c|}{$17.3 \%$} \\
\hline Single parent &
\end{tabular}

occasional exposure of children to smoking visitors, and/or the family members (Table 2). Children having low-educated parents more often reported they do not drive by car.

In the whole cohort, $67.5 \%$ children did not smoke even one puff yet; $17.2 \%$ reported one single attempt; and $15.4 \%$ smoked repeatedly. The level of parents' education had no influence on children's current smoking experimentation or on their actual decision about smoking in the future. Although children of higheducated mothers reported more often they would not smoke in the future, the differences were not significant. Parent's education have no influence on their willingness to provide cigarettes to their children. (Table 3).

In the group of children living in reconstituted (step) families were more children willing to experiment with smoking and to smoke in the future, but when compared with complete and single families these differences were not significant (Table 4). However, when the level of maternal education was combined with the family status, significant differences were found. Compared to group living with two biological parents of whom mother attained higher education, children from other groups more often reported current experimentation with smoking (the differences were significant for children in single families with middle educated mothers and step families with low educated mothers). Children from single and/or step families with middle and/or low educated mothers expressed significantly less often their decision not to smoke in the future. While children living in single families more often hesitated about their future smoking, children from reconstituted (step) families were significantly more often decided to smoke (Table 5).

No significant differences were found in other markers of knowledge and attitudes between children from analysed social family groups:

- $77 \%$ of children declared that smoking is associated with alcohol and other drugs use.

- Nearly $74 \%$ of children thought that majority of smokers are drug addicted. Almost two thirds of children (65\%) have mentioned the communication with their parents about smoking.

- More than $72 \%$ of children knew that smoking is prohibited in public places and another $23 \%$ of children knew that smokers can damage no-smoking people; only less that $5 \%$ suggested that smokers can smoke everywhere.

- More than one third of pupils (36.3\%) tried to ask smokers not to smoke in their immediate environment, but only about $17 \%$ of them succeeded. Another one third of children was afraid to raise this question and the rest felt no need of it.

- Neither parental education, nor family status influenced on the children's opinions about adults' smoking: only $2,3 \%$ of them like smoking women and 4.4\% like smoking men; while almost $90 \%$ dislike smoking women and $83 \%$ dislike smoking men; and $8 \%$ or $13 \%$ of children respectively, reported ambivalent attitudes to smoking women and/or men.

\section{DISCUSSION}

The cohort participating in the interventional school-based anti-smoking programme "Non-Smoking Is Normal" is substantially younger than the samples of adolescents described in majority of published studies. The lower reading and writing skills of pupils in the 1st to 5th grade present serious limit as to the content and the 
Table 2. Children's exposure to passive smoking according to parental education (\% of answers)

\begin{tabular}{|c|c|c|c|c|c|}
\hline \multirow{2}{*}{ Exposure at home } & \multicolumn{5}{|c|}{ Mother's education } \\
\hline & High & Middle & $\mathrm{RR}(95 \% \mathrm{Cl})$ & Low & $\mathrm{RR}(95 \% \mathrm{Cl})$ \\
\hline Nobody smokes & 60.5 & $49.8^{* *}$ & $1.22(1.05-1.41)$ & $41.8^{* *}$ & $1.47(1.05-2.06)$ \\
\hline Visitors & 10.3 & 9.3 & ns & 10.9 & ns \\
\hline From time to time & 13.5 & 18.6 & ns & 16.4 & ns \\
\hline \multirow[t]{2}{*}{ Daily } & 15.7 & $22.3^{*}$ & $1.15(1.03-1.29)$ & $30.9^{*}$ & $1.38(1.04-1.83)$ \\
\hline & \multicolumn{5}{|c|}{ Father's education } \\
\hline Nobody smokes & 60.7 & $51.2^{*}$ & $1.18(1.02-1.37)$ & $37.7^{\star *}$ & $1.64(1.14-2.36)$ \\
\hline Visitors & 9.2 & 9.9 & ns & 11.3 & ns \\
\hline From time to time & 15.0 & 16.4 & ns & 18.9 & ns \\
\hline Daily & 15.0 & $22.5^{*}$ & $1.15(1.03-1.29)$ & $32.1^{* *}$ & $1.48(1.09-2.02)$ \\
\hline \multirow{2}{*}{ Exposure in cars } & \multicolumn{5}{|c|}{ Mother's education } \\
\hline & High & Middle & $\operatorname{RR}(95 \% \mathrm{Cl})$ & Low & $\mathrm{RR}(95 \% \mathrm{Cl})$ \\
\hline Child does not use the car & 6.7 & 7.0 & ns & $21.4^{* * *}$ & $0.30(0.14-0.64)$ \\
\hline Nobody smokes & 81.1 & 78.3 & ns & $58.9^{\star *}$ & $1.38(1.09-1.73)$ \\
\hline From time to time & 8.9 & 10.5 & ns & 19.6 & ns \\
\hline \multirow[t]{2}{*}{ Very often } & 2.8 & 4.2 & ns & 0.0 & ns \\
\hline & \multicolumn{5}{|c|}{ Fathers's education } \\
\hline Child does not use the car & 5.4 & 7.6 & ns & $18.9^{* * *}$ & $0.29(0.13-0.64)$ \\
\hline Nobody smokes & 85.3 & $76.4^{* *}$ & $1.12(1.03-1.21)$ & $62.3^{* * *}$ & $1.35(1.09-1.67)$ \\
\hline From time to time & 6.9 & 12.5 & ns & 11.3 & ns \\
\hline Very often & 2.5 & 3.5 & ns & 7.5 & ns \\
\hline
\end{tabular}

Statistic significance compared frequency of answers of high educated to middle and low educated groups; ${ }^{*} p<0.05$, ${ }^{* *} p<0.01,{ }^{* * *} p<0.001$.

Bold numbers indicate significantly different values.

extent of questionnaire. The number of questions is limited and their formulation must allow for simple answers. Due to these objective limitations, the hypothetical associations cannot be studied in details.

The contemporary experimentation with smoking and decision about smoking in the future was similar in groups with different family status. When maternal education was involved into the evaluation, significantly higher number of children reporting current and future non-smoking was found in families with two biological parents where mother attained higher education.

It has been described that high level of parental support and moderate levels of control are associated with lower risk of children's smoking and drinking. Such optimal conditions are usually provided by two biological and married parents (2). Those living in cohabitation tend to be unconventional and they often also adopt risky behaviour themselves including smoking and drinking. In single-parent families, step families or cohabitating families adolescents are more likely used to smoke and drink alcohol than those living with two biological and married parents $(2,31,37-39)$.

Significantly more children living in families with lower educated parents were exposed to the smoking environment which represents both dangerous chemical hazards and bad behavioural models.

Parents' education has been negatively associated not only with adults' smoking, but also with teens' smoking, while the family income had only modest relation to adolescent smoking behaviour $(2,40)$. In studies, the lowest parental education level was in cohabitating families and single-parent families, the highest education had married two biological parent families $(2,41)$. The most common possible explanation of the relationships of education and smoking is the fact that more educated individuals are better informed on the health risks of smoking and this information is transferred to the children (42). The previous explanation offered hypothesis that less educated people might be more day to day-oriented and more likely to become addicted (43).

Despite of it, no important influence of paternal education on children's opinions and attitudes or their current smoking or decision about future smoking were found. The similar results described authors of Slovakia Global Youth Tobacco Survey 2007 (21).

The current experimentation with smoking and decision about smoking in the future was also similar in groups with different family status. When maternal education was made part of the evaluation, significantly higher number of children reporting current and future non-smoking was living in families with two biological parents where mother was high educated.

The frequency of communication about smoking was similar in all groups of children regardless the parents' level of education. Parents maybe use the same form of discussion. Unfortunately, only small group of parents was interested to get familiarised with the informative brochure which was prepared to help them when "talking about smoking".

Anti-smoking messages, rules and behaviour within the family environment are particularly critical during the developmental phase when children and adolescents decide about their smoking 
Table 3. Children's smoking behaviour and decisions about future smoking according to parental education (\% of answers)

\begin{tabular}{|c|c|c|c|c|c|c|}
\hline \multirow{2}{*}{ Lifetime smoking } & \multicolumn{3}{|c|}{ Mother's education } & \multicolumn{3}{|c|}{ Father's education } \\
\hline & Low & Middle & High & Low & Middle & High \\
\hline Not even one puff & 67.8 & 68.4 & 66.8 & 66.1 & $65.8 \%$ & 69.8 \\
\hline One single attempt & 16.1 & 15.0 & 19.6 & 24.5 & $16.0 \%$ & 17.3 \\
\hline Repeatedly & 16.1 & 16.6 & 13.6 & 9.4 & $18.2 \%$ & 12.9 \\
\hline \multicolumn{7}{|l|}{ Smoking in the future } \\
\hline Certainly no & 50.0 & 48.5 & 60.5 & 56.6 & $48.9 \%$ & 56.7 \\
\hline Probably no & 14.2 & 19.8 & 19.7 & 11.3 & $20.9 \%$ & 20.4 \\
\hline Don't know & 30.4 & 25.8 & 15.8 & 28.3 & $24.6 \%$ & 19.4 \\
\hline Probably yes & 1.8 & 4.7 & 2.8 & 3.8 & $4.4 \%$ & 2.0 \\
\hline Certainly yes & 3.6 & 1.2 & 1.2 & 0.0 & $1.2 \%$ & 1.5 \\
\hline
\end{tabular}

Table 4. Children's smoking behaviour and decision about future smoking according to family status (\% of answers)

\begin{tabular}{|l|c|c|c|}
\hline \multirow{2}{*}{ Smoking } & \multicolumn{2}{|c|}{ Family } \\
\cline { 2 - 4 } & Complete & Reconstituted & Single \\
\hline No one puff yet & 70.1 & 65.8 & 10.4 \\
\hline One single attempt & 17.9 & 22.0 & 12.6 \\
\hline Repeatedly & 12.0 & 12.2 & 63.8 \\
\hline Smoking in the future & \multicolumn{2}{|c|}{} \\
\hline No (certainly + probably) & 71.0 & 65.1 & 28.6 \\
\hline Don't know & 23.3 & 24.1 & 7.6 \\
\hline Yes (certainly + probably) & 5.7 & 10.8 & 8.1 \\
\hline Cigarette obtained from parents & 10.9 & 4.5 & \\
\hline
\end{tabular}

Table 5. Children's smoking behaviour and decisions about future smoking according to family status and maternal education (\% of answers)

\begin{tabular}{|l|c|c|c|c|c|c|c|c|c|}
\hline \multirow{2}{*}{$\begin{array}{l}\text { Family + mother's } \\
\text { education }\end{array}$} & \multicolumn{4}{|c|}{ Smoked } & \multicolumn{5}{c|}{ Will smoke in future } \\
\cline { 2 - 10 } & Yes & No & RR $(95 \%$ Cl) & Yes & RR $(95 \%$ Cl) & Not know & RR $(95 \%$ Cl) & No & RR (95\% Cl) \\
\hline Complete + high & 20.0 & 80.0 & & 1.6 & & 13.5 & & 84.9 & \\
\hline Step + middle & 31.1 & 68.9 & ns & $8.7^{*}$ & $1.22(1.01-1.48)$ & 21.7 & ns & $69.6^{*}$ & $0.50(0.29-0.87)$ \\
\hline Single + middle & 35.4 & $64.6^{*}$ & $1.23(1.04-1.46)$ & 9.0 & ns & $30.8^{* * *}$ & $1.34(1.13-1.50)$ & $60.2^{* * *}$ & $0.42(0.26-0.66)$ \\
\hline Step + low & 40.4 & $59.6^{*}$ & $1.30(0.84-2.01)$ & $16.6^{*}$ & $1.30(0.84-2.01)$ & 25.0 & ns & $58.4^{* *}$ & $0.36(0.18-0.73)$ \\
\hline Single + low & 25.1 & 74.9 & ns & 6.3 & ns & $50.0^{* * *}$ & $2.1(1.18-3.42)$ & $43.7^{* * *}$ & $0.260 .15-0.45$ \\
\hline
\end{tabular}

The complete family with high-educated mothers was the base for the statistic evaluation of differences found in other groups; ${ }^{*} p<0.05 ;{ }^{* *} p<0.01$; ${ }^{* * *} p<0.001$

initiation (22). From this point of view, two results obtained in our study are important for development of guidelines aiming at protection of young children against their involuntary exposure to passive smoking. About $10 \%$ of children described that only visitors smoke in their homes. The appropriate medial message can easily enhance the number of never exposed children if their no-smoking parents would ask their friends or relatives to respect the protection of children and other non-smokers. It may be the first step for propagation of "smoke-free homes".
If another $17 \%$ of smokers, who smoke only occasionally at their homes, will accept the strict anti-smoking rules protecting children, the next generation of the young population may be positively influenced.

There is a wide discussion on how to enhance the protection of children. Besides others, the appropriate legislation on smoking bans at homes and vehicles where children are passengers as an important health and smoking prevention has already been enacted in number of countries such as the USA, Canada, Australia, Mau- 
ritius, South Africa, and Bahrain $(13,44)$. It must be mentioned that not only non-smokers, but even majority of smokers support banning smoking in cars and homes with children (45). However, for many political representatives including those in the Czech Republic such legislative control measures are not acceptable. Thus the main goal is to replace the tolerant attitudes of society to smoking by general opinion, that such behaviour "is not normal".

\section{CONCLUSIONS}

These findings provide evidence that:

- Family structure and parental education are the factors associated with different levels of influence on children risk behaviour.

- Parental support, control, and modelling have an important role in forming social bonds, opinions, and behaviour patterns.

- In our study, the parental education has significantly influenced children's exposure to passive smoking at homes and cars, but had no effect on children's opinions and attitudes to smoking.

- The combination of mothers' education and family status significantly lowered the frequency of current experimentation and decision about future smoking among children living in families with two biological parents and high educated mother.

- It is necessary to seek ways for improving parental concern about smoking prevention.

\section{Acknowledgement:}

The study was supported by the Research Grant of MŠMT CR No. 216 22421 and League against Cancer, Prague.

\section{REFERENCES}

1. US Department of Health and Human Services. Healthy people 2010: understanding and improving health. Washington, DC.: Government Printing Office; 2000.

2. Brown SL, Rinelli LN. Family structure, family processes, and adolescent smoking and drinking. J Res Adolesc. 2010 Jun 1;20(2):259-73.

3. Kobus K. Peers and adolescent smoking. Addiction. 2003 May;98 Suppl $1: 37-55$.

4. Steinberg L, Monahan KC. Age differences in resistance to peer influence. Dev Psychol. 2007 Nov;43(6):1531-43.

5. Kameda T, Takezawa M, Hastie R. Where do social norms come from: the example of communal sharing. Curr Dir Psychol Sci. 2005;14(6):331-4

6. Simons-Morton B. Social influences on adolescent substance use. Am J Health Behav. 2007 Nov-Dec;31(6):672-84

7. Hoffman BR, Monge PR, Chou CP, Valente TW. Perceived peer influence and peer selection on adolescent smoking. Addict Behav. 2007 Aug;32(8):1546-54.

8. Sakuma KL, Sun P, Unger JB, Johnson CA. Evaluating depressive symptom interactions on adolescent smoking prevention program mediators: a mediated moderation analysis. Nicotine Tob Res. 2010 Nov;12(11):1099107.

9. Göhlmann S, Schmidt CM, Tauchmann H. Smoking initiation in Germany: the role of intergenerational transmission. Health Econ. 2010 Feb;19(2):227-42

10. Lewis TL, Kotch J, Wiley TR, Litrownik AJ, English DJ, Thompson R, et al. Internalizing problems: a potential pathway from childhood maltreatment to adolescent smoking. J Adolesc Health. 2011 Mar;48(3):247-52.

11. Simons-Morton BG, Farhat T. Recent findings on peer group influences on adolescent smoking. J Prim Prev. 2010 Aug;31(4):191-208.

12. Andrews JA, Tildesley E, Hops H, Li F. The influence of peers on young adult substance use. Health Psychol. 2002 Jul;21(4):349-57.

13. Schultz AS, Nowatzki J, Dunn DA, Griffith EJ. Effects of socialization in the household on youth susceptibility to smoking: a secondary analysis of the 2004/05 Canadian Youth Smoking Survey. Chronic Dis Can. 2010 Jun;30(3):71-7.

14. Bailey SL, Ennett ST, Ringwalt CL. Potential mediators, moderators, or independent effects in the relationship between parents' former and current cigarette use and their children's cigarette use. Addict Behav. 1993 Nov-Dec;18(6):601-21.

15. Bantle C, Haisken-DeNew JP. Smoke signals: the intergeneration transmission of smoking behavior. Discussion Paper. 2002;227:1-23.

16. Andersen MR, Leroux BG, Bricker JB, Rajan KB, Peterson AV Jr Antismoking parenting practices are associated with reduced rates of adolescent smoking. Arch Pediatr Adolesc Med. 2004 Apr;158(4):348-52.

17. Komro KA, McCarty MC, Forster JL, Blaine TM, Chen V. Parental, family, and home characteristics associated with cigarette smoking among adolescents. Am J Health Promot. 2003 May-Jun;17(5):291-9.

18. Leatherdale ST, McDonald PW, Cameron R, Brown KS. A multilevel analysis examining the relationship between social influences for smoking and smoking onset. Am J Health Behav. 2005 Nov-Dec;29(6):520-30.

19. Bricker JB, Peterson AV, Robyn Andersen M, Leroux BG, Bharat Rajan K, Sarason IG. Close friends', parents', and older siblings' smoking: reevaluating their influence on children's smoking. Nicotine Tob Res. 2006 Apr;8(2):217-26

20. Powell L, Chaloupka F. Parents, public policy, and youth smoking. J Policy Anal Manage. 2005;24(1):93-112.

21. Baška T, Warren CW, Hudečková H, Ochaba R, St'astný P, Lea V, et al. The role of family background on cigarette smoking among adolescent school children in Slovakia: findings from the 2007 Slovakia Global Youth Tobacco Survey. Int J Public Health. 2010 Dec;55(6):591-7.

22. Pierce JP, Choi WS, Gilpin EA, Farkas AJ, Merritt RK. Validation of susceptibility as a predictor of which adolescents take up smoking in the United States. Health Psychol. 1996 Sep;15(5):355-61.

23. Loureiro M, Sanz-de-Galdeano A, Vuri D. Smoking habits: like father, like son, like mother, like daughter. IZA Discussion Paper. 2006;2279.

24. Mercken L, Candel M, Willems P, de Vries H. Disentangling social selection and social influence effects on adolescent smoking: the importance of reciprocity in friendships. Addiction. 2007 Sep;102(9):1483-92.

25. Urberg KA, Luo Q, Pilgrim C, Degirmencioglu SM. A two-stage mode of peer influence in adolescent substance use: individual and relationshipspecific differences in susceptibility to influence. Addict Behav. 2003 Sep;28(7):1243-56. Erratum in: Addict Behav. 2004 May;29(3):639.

26. Wakefield MA, Chaloupka FJ, Kaufman NJ, Orleans CT, Barker DC, Ruel EE. Effect of restrictions on smoking at home, at school, and in public places on teenage smoking: cross sectional study. BMJ. 2000 Aug 5;321(7257):333-7. Erratum in: BMJ. 2000 Sep 9;31(7261):623.

27. Rees VW, Connolly GN. Measuring air quality to protect children from secondhand smoke in cars. Am J Prev Med. 2006 Nov;31(5):363-8.

28. Sendzik T, Fong GT, Travers MJ, Hyland A. An experimental investigation of tobacco smoke pollution in cars. Nicotine Tob Res. 2009 Jun;11(6):62734.

29. Jackson C, Dickinson D. Enabling parents who smoke to prevent their children from initiating smoking: results from a 3-year intervention evaluation. Arch Pediatr Adolesc Med. 2006 Jan;160(1):56-62.

30. Mahabee-Gittens EM, Ding L, Gordon JS, Huang B. Agreement between parents and youth on measures of anti-smoking socialization. J Child Adolesc Subst Abuse. 2010 Apr 1;19(2):158-70.

31. DeLeire T, Kalil A. How do cohabiting couples with children spend their money? J Marriage Fam. 2005;67(2):286-95.

32. de Leeuw R, Scholte R, Vermulst A, Engels R. The relation between smoking-specific parenting and smoking trajectories of adolescents: how are changes in parenting related to changes in smoking? Psychol Health. 2010 Oct;25(8):999-1021

33. Harakeh Z, Scholte RH, de Vries H, Engels RC. Parental rules and communication: their association with adolescent smoking. Addiction. 2005 Jun;100(6):862-70.

34. Otten R, Harakeh Z, Vermulst AA, Van den Eijnden RJ, Engels RC. Frequency and quality of parental communication as antecedents of adolescent smoking cognitions and smoking onset. Psychol Addict Behav. 2007 Mar;21(1):1-12.

35. den Exter Blokland EA, Hale WW 3rd, Meeus W, Engels RC. Parental anti-smoking socialization. associations between parental anti-smoking socialization practices and early adolescent smoking initiation. Eur Addict Res. 2006;12(1):25-32.

36. Ennett ST, Bauman KE, Foshee VA, Pemberton M, Hicks KA. Parentchild communication about adolescent tobacco and alcohol use: what do parents say and does it affect youth behavior? J Marriage Fam. 2001;63(1):48-62. 
37. Deleire T, Kalil A. Good things come in threes: single-parent multigenerational family structure and adolescent adjustment. Demography. 2002 May;39(2):393-413.

38. Bergman MM, Scott J. Young adolescents' wellbeing and health-risk behaviours: gender and socio-economic differences. J Adolesc. 2001 Apr;24(2):183-97.

39. Griesbach D, Amos A, Currie C. Adolescent smoking and family structure in Europe. Soc Sci Med. 2003 Jan;56(1):41-52.

40. Friestad C, Pirkis J, Biehl M, Irwin CE Jr. Socioeconomic patterning of smoking, sedentary lifestyle, and overweight status among adolescents in Norway and the United States. J Adolesc Health. 2003 Oct;33(4):275-8.

41. Manning WD, Brown SL. Children's economic well-being in married and cohabiting parent families. J Marriage Fam. 2006;68(2):345-62.

42. Madden D. Tobacco taxes and starting and quitting smoking: does the effect differ by education? Appl Econ. 2007;39:613-27.
43. Becker GS, Murphy KM. A theory of rational addiction. J Polit Econ. 1988;96(4):675-700

44. Nowatzki J, Schultz AS, Griffith EJ. Discrepancies between youth and parent perceptions of their household environment relevant to smoking: a secondary analysis of the 2004/05 Canadian Youth Smoking Survey. Chronic Dis Can. 2010 Jun;30(3):78-83.

45. Hitchman SC, Fong GT, Zanna MP, Hyland A, Bansal-Travers M. Support and correlates of support for banning smoking in cars with children: findings from the ITC Four Country Survey. Eur J Public Health. 2011 Jun;21(3):360-5.

Received November 24, 2010 Accepted in revised form November 25, 2011 